\title{
What really happened with SARS?
}

\author{
SARS Unmasked: Risk Communication of \\ Pandemics and Influenza in Canada \\ Michael G. Tyshenko with assistance from \\ Cathy Paterson \\ McGill-Queen's University Press; 2010.
}

$\mathrm{T}$ he 2003 SARS outbreak was a defining professional experience for a generation of Canadian public health professionals and administrators. Seven years on, people have been dismissed, legislation rewritten, governments dumped, agencies created and court cases settled. We've established the facts, we understand the science, but still, even now, the question remains: what really happened?

This new book, SARS Unmasked: Risk Communication of Pandemics and Influenza in Canada, tackles this oftasked question but searches for an answer in unusual places. Author Michael Tyshenko - a molecular biologist by training - wades into the murky depths of risk perception, information management and the politics of emergencies to reconsider the SARS crisis. In doing so, he lays bare the complexity of any public health emergency and underscores that success will demand a broad and integrated approach to risk management.

Tyshenko walks through the basics of the outbreak including the timeline of the first cases, the science of the virus and the comparative experience among other affected nations. But, crucially, he does not stop there.

SARS is deconstructed through the lens of the social amplification of risk theory, an interdisciplinary framework that argues that any given risk interacts with psychological, social and cultural factors to either increase or decrease risk perception. It helps in understanding SARS, given not only the evident gap between risk and risk perception but also the myriad other dynamics - social, economic and political - that at times dominated the media coverage.

Tyshenko draws from the risk communication literature and argues that key characteristics of the outbreak, for exam-

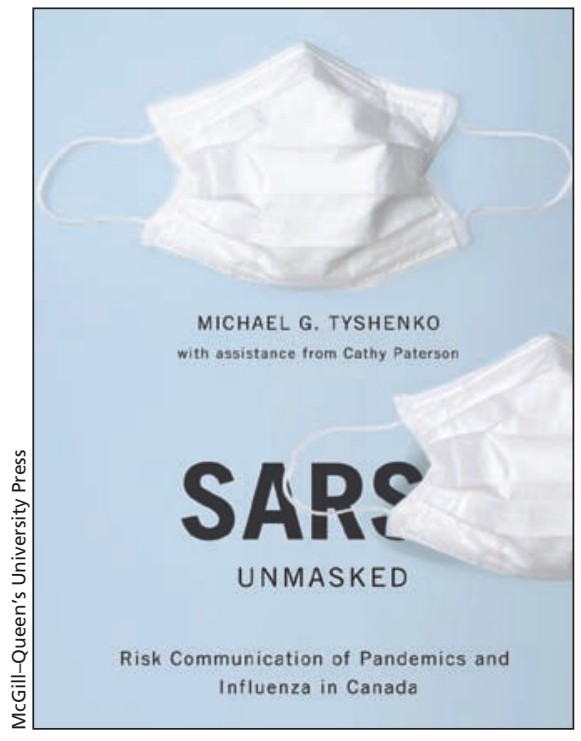

ple, its novelty, its unknown characteristics and its potential social and economic impact, resulted in exaggerated media "overkill" which, in turn, fed the social amplification of the actual risk of the disease. Quite brilliantly, the SARS outbreak is contrasted with the outbreak of Clostridium difficile in Montréal, Quebec at around the same time. That outbreak, which was responsible for twice as many deaths as the Toronto SARS outbreak, unfolded in comparative anonymity except, of course, for the victims, families and staff directly affected.

SARS Unmasked, however, is a victim of timing. Its release on the heels of the H1N1 pandemic no doubt elevates interest in the book, but its commentary and recommendations on pandemics do not touch H1N1. With the pandemic only recently being declared officially over, clearly Tyshenko is not the type to rush in with a last-minute addendum.

However, the sections on pandemic influenza preparedness work from the World Health Organization's (WHO) pre-H1N1 planning assumptions did include the potential mutation of the highly pathogenic $\mathrm{H} 5 \mathrm{~N} 1$ or bird flu virus. In the midst of at times scathing international criticism of the WHO's management - including risk communication management - of the H1N1 pandemic, this threatens to undermine many key contributions of the book. For example, there is a very useful summary of the many SARS reports and reviews. But surely the book's value is in comparing the SARS event findings with actual performance during the H1N1 pandemic. Was coordination better among the health partners? Was planning any more effective? Did the event managers actively listen to those affected and involved?

But if SARS Unmasked suffers from what is excludes, Tyshenko must be lauded for other key inclusions, none more so than the contributions of Cathy Paterson, a Toronto-based nurse and veteran of the SARS front lines. Her firsthand account coupled with the personal stories of other health care providers, describes the fear, isolation and ongoing psychological impact of the experience. It brings the analysis to life, but does more than simply provide colour.

For a largely hospital-based outbreak such as SARS in Canada, it was the professional commitment and required behaviour change of nurses and other health care staff that were the key to effective outbreak control. Their sense of betrayal, confusion and inability to contribute their own perspective to the event management strategy represented the greatest risk to success. Indeed, the most important point of SARS Unmasked is that risk communication in public health emergencies is not about a clever turn of phrase or a "Clinton-esque" expression of empathy but about the strategic use of communication - two-way communication - to effectively manage risk, limit socioeconomic disruption and, ultimately, save lives.

\section{John Rainford MPA \\ Research fellow \\ McLaughlin Centre \\ University of Ottawa \\ Ottawa, Ont.}

John Rainford was most recently the lead for risk communication capacity building at the World Health Organization and was the Chief, Crisis Communication at Health Canada during the 2003 SARS outbreak.

CMAJ 2011.DOI:10.1503/cmaj.101167 